\title{
Surface Landmarks do not Correspond to Exact Levels of the Cervical Spine: References According to the Sex, Age and Height
}

\author{
Chang Hyun $\mathrm{Oh}^{1}$, Gyu Yeul $\mathrm{Ji}^{2}$, Seung Hwan Yoon ${ }^{3}$, Dongkeun Hyun ${ }^{3}$, \\ Chun Gil Choi ${ }^{4}$, Hyun Kyoung Lim ${ }^{4}$, A Reum Jang ${ }^{1}$ \\ ${ }^{I}$ Spine and Joint Research Institute, Teun Teun Hospital, Seoul, \\ ${ }^{2}$ Department of Neurosurgery, Yonsei University College of Medicine, Seoul, \\ Departments of ${ }^{3}$ Neurosurgery, ${ }^{4}$ Anesthesiology and Pain Medicine, Inha University College of Medicine, Incheon, Korea
}

Objective: A general orientation along the cervical spine could be estimated by external landmarks, and it was useful, quick and less exposable to radiation, but, sometimes it gave reference confusion of target cervical level. The authors reviewed the corresponding between the neck external landmarks and cervical levels.

Methods: Totally 1,031 cervical lateral radiographs of different patients were reviewed in single university hospital. Its compositions were 534 of males and 497 females; 86 of second decades (10-19 years-old), 169 of third decades, 159 of fourth decades, 209 of fifth decades, 275 of sixth decades, and 133 of more than seventh decades (>60 years-old). Reference external landmarks (mandible, hyoid bone, thyroid cartilage, and cricothyroid membrane) with compounding factors were reviewed.

Results: The reference levels of cervical landmarks were C2.13 with mandible angle, C3.54 with hyoid bone, C5.12 with thyroid cartilage, and C6.01 with cricothyroid membrane. The reference levels of cervical landmarks were differently observed by sex, age, and somatometric measurement (height) accordingly mandible angle from $\mathrm{C} 1$ to $\mathrm{C}$, hyoid bone from disc level of $\mathrm{C} 2$ and $\mathrm{C} 3$ to $\mathrm{C} 5$, thyroid cartilage from disc level of $\mathrm{C} 3$ and $\mathrm{C} 4$ to $\mathrm{C} 7$, and cricothyroid membrane from $\mathrm{C} 4$ to disc level of $\mathrm{C} 7$ and $\mathrm{T} 1$.

Conclusion: Surface landmarks only provide general reference points, but not correspond to exact levels of the cervical spine. Intraoperative fluoroscopy ensures a more precise placement to the targeted cervical level.

Key Words: External landmark $\cdot$ Cervical level $\cdot$ Mandible $\cdot$ Hyoid bone $\cdot$ Thyroid cartilage $\cdot$ Cricothyroid membrane

\section{INTRODUCTION}

The goal of the cervical surgery is to relieve the compression on the nerves and/or spinal cord, and anterior or posterior cervical approach is used to access the cervical spine depend

- Received: March 19, 2014 - Revised: May 2, 2014

- Accepted: May 30, 2014

Corresponding Author: Seung Hwan Yoon, MD, PhD

Department of Neurosurgery, Inha University College of Medicine

Shinheung-dong, Jung-gu, Incheon 400-711, Korea

Tel: +82-32-890-2370, Fax: +82-32-890-2374

E-mail: nsyoon@gmail.com

*No external funding was received for this study.

*The authors declare that they have no proprietary, commercial, or financial interests that could be construed to have inappropriately influenced this study.

*This study has not been presented in part elsewhere.

$\otimes T h i s$ is an Open Access article distributed under the terms of the Creative

Commons Attribution Non-Commercial License (http://creativecommons.org/ licenses/by-nc/3.0/) which permits unrestricted non-commercial use, distribution, and reproduction in any medium, provided the original work is properly cited. on the type of surgery required ${ }^{6}$. The advantages of anterior approach is it allows better access to the spine ${ }^{4)}$. The anterior approach can allow the surgeon access to almost the entire cervical spine, and often helps maintain the normal curvature of the spine $e^{4)}$. A general orientation along the cervical spine can be estimated by external landmarks ${ }^{2)}$. The textbook of Korean Spinal Neurosurgery Society provide that general external landmarks: the hyoid bone corresponds to $\mathrm{C} 3$; the thyroid cartilage corresponds to C4-5; and the cricothyroid membrane identifies the $\mathrm{C} 6$ vertebral level ${ }^{3}$. Cervical spine level estimation according to the external landmarks is useful, quick and less exposable to radiation, but, sometimes cervical level confusion to the target cervical level could be happen. Herein, the authors reviewed the corresponding between the neck external landmarks and cervical levels.

\section{MATERIALS AND METHODS}

Between January and December 2013, the authors retro- 
spectively reviewed cervical lateral radiographs which were taken in single university hospital by various cervical problems. All radiographs and the patient's information such as sex, age, and heights were collected using the retrograde medical chart review. The cervical lateral radiographs were checked in the standing position with the closed mouth. The neck external landmarks were defined as mandible angle, hyoid, thyroid, and cricothyroid in radiographs: mandible angle as the posterior border at the junction of the lower border of the ramus of the mandible; hyoid as the superior surface of anterior margin of hyoid; thyroid as the inferior margin of laryngeal incisures; and crocithyroid as the lower border of the laryngeal prominence which connected to median cricothyroid liga-
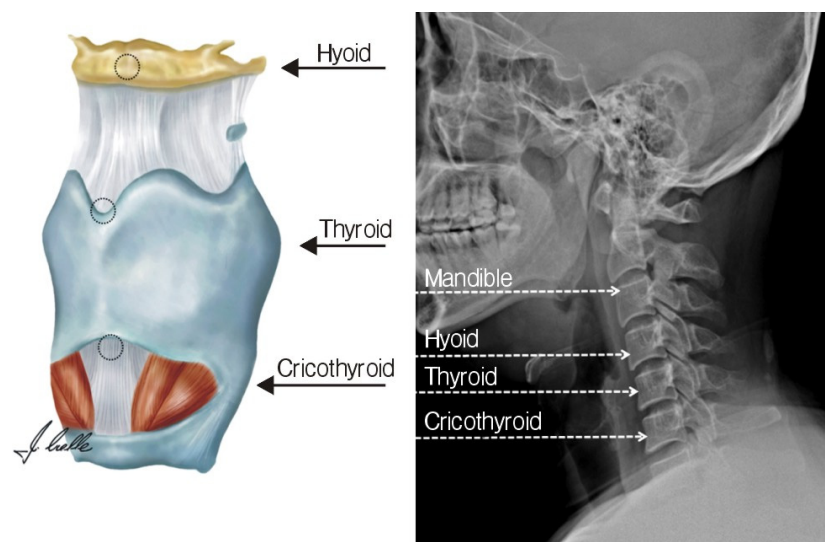

Fig. 1. Cenvical external landmark by cervical lateral radiographs. ment. These landmarks and horizontally lined to cervical spine were corresponded in radiographs, and each reference level were measured as cervical vertebral body level or cervical disc level (Fig. 1). For example, if the horizontal line were corresponded to C3 vertebral level, it was measured as "C3", and if the line were corresponded to the disc level between $\mathrm{C} 5$ and C6, it was measured as "C5.5". The authors used the imaging programs for horizontal line drawing between landmarks and cervical level. The results are expressed as the mean \pm standard deviation. Paired Student t-test was used to assess the statistical differences using SAS software for Windows (SAS Institute Inc., Cary, NC). A p $<0.050$ was considered significant statistical difference.

\section{RESULTS}

The average reference levels of cervical landmarks were C2.13 with mandible angle, C3.54 with hyoid, C5.12 with thyroid, and C6.01 with cricothyroid (Table 1, Fig. 2 and 3). The reference levels of cervical landmarks were differently observed by sex, age, and height accordingly mandible from disc level of $\mathrm{C} 1$ and $\mathrm{C} 2$ to $\mathrm{C} 3$, hyoid from disc level of $\mathrm{C} 2$ and $\mathrm{C} 3$ to $\mathrm{C} 5$, thyroid from disc level of $\mathrm{C} 3$ and $\mathrm{C} 4$ to $\mathrm{C} 7$, and cricothyroid from $\mathrm{C} 4$ to disc level of $\mathrm{C} 7$ and T1. The reference levels were statistically differently observed according to the sex, age, and height $(\mathrm{p}<0.05)$, but the average difference were not meaningful to clinics because of its minimal

Table 1. The average reference levels of cervical landmarks (YO: years old)

\begin{tabular}{lclllc}
\hline \hline \multicolumn{1}{c}{ Category } & $\mathrm{N}$ & \multicolumn{1}{c}{ Mandible angle } & \multicolumn{1}{c}{ Hyoid bone } & Thyroid cartilage & Cricohyoid membrane \\
\hline Total & 1,031 & $2.13 \pm 0.28(1.5-3)$ & $3.54 \pm 0.50[2.5-5)$ & $5.12 \pm 0.67[3.5-7)$ & $6.01 \pm 0.57[4-7.5)$ \\
Male & 534 & $2.16 \pm 0.31(1.5-3)$ & $3.77 \pm 0.46(2.5-5)$ & $5.52 \pm 0.55(4-7)$ & $6.16 \pm 0.45(4-7.5)$ \\
Female & 497 & $2.10 \pm 0.23(1.5-3)$ & $3.29 \pm 0.42(2.5-5)$ & $4.69 \pm 0.49(3.5-6)$ & $5.84 \pm 0.63(4-7)$ \\
& p-value & 0.001 & $<0.001$ & $<0.001$ & $<0.001$ \\
Height $(>170 \mathrm{~cm})$ & 173 & $2.16 \pm 0.29(2-3)$ & $3.77 \pm 0.50(2.5-5)$ & $5.47 \pm 0.64(4-7)$ & $6.17 \pm 0.45(4-7.5)$ \\
Height $(<170 \mathrm{~cm})$ & 428 & $2.12 \pm 0.25(1-3)$ & $3.43 \pm 0.48(2.5-5)$ & $5.01 \pm 0.65(3.5-6.5)$ & $5.93 \pm 0.62(4-7)$ \\
& $p-v a l u e$ & 0.074 & $<0.001$ & $<0.001$ & $<0.001$ \\
Height $(>180 \mathrm{~cm})$ & 19 & $2.21 \pm 0.35(2-3)$ & $3.89 \pm 0.32(3-4.5)$ & $5.55 \pm 0.50(5-6.5)$ & $6.42 \pm 0.58(5-7.5)$ \\
Height $(<180 \mathrm{~cm})$ & 582 & $2.13 \pm 0.26(1.5-3)$ & $3.51 \pm 0.51(2.5-5)$ & $5.13 \pm 0.68(3.5-7)$ & $5.99 \pm 0.58(4-7)$ \\
& $\mathrm{p}$ & 0.186 & 0.001 & 0.007 & 0.001 \\
Age 10-19 YO & 86 & $2.20 \pm 0.35(2-3)$ & $3.51 \pm 0.49(2.5-5)$ & $5.14 \pm 0.84(4-6.5)$ & $5.73 \pm 0.71(4-7.5)$ \\
Age 20-29 YO & 169 & $2.18 \pm 0.33(1.5-3)$ & $3.48 \pm 0.45(2.5-5)$ & $4.81 \pm 0.61(3.5-7)$ & $6.14 \pm 0.45(4-7.5)$ \\
Age 30-39 YO & 159 & $2.10 \pm 0.22(1.5-3)$ & $3.55 \pm 0.47(2.5-4.5)$ & $4.94 \pm 0.56(4-6)$ & $5.95 \pm 0.69(4-7.5)$ \\
Age 40-49 YO & 209 & $2.09 \pm 0.26(1.5-3)$ & $3.53 \pm 0.56(2.5-5)$ & $5.30 \pm 0.59(4-6.5)$ & $5.69 \pm 0.63(4-7)$ \\
Age 50-59 YO & 275 & $2.14 \pm 0.27(1.5-3)$ & $3.53 \pm 0.51(2.5-5)$ & $5.18 \pm 0.68(3.5-7)$ & $6.18 \pm 0.35(5-7)$ \\
Age $>60 \mathrm{YO}$ & 133 & $2.12 \pm 0.24(1.5-3)$ & $3.67 \pm 0.50(3-5)$ & $5.28 \pm 0.63(4-7)$ & $6.24 \pm 0.37(5.5-7)$ \\
\hline
\end{tabular}



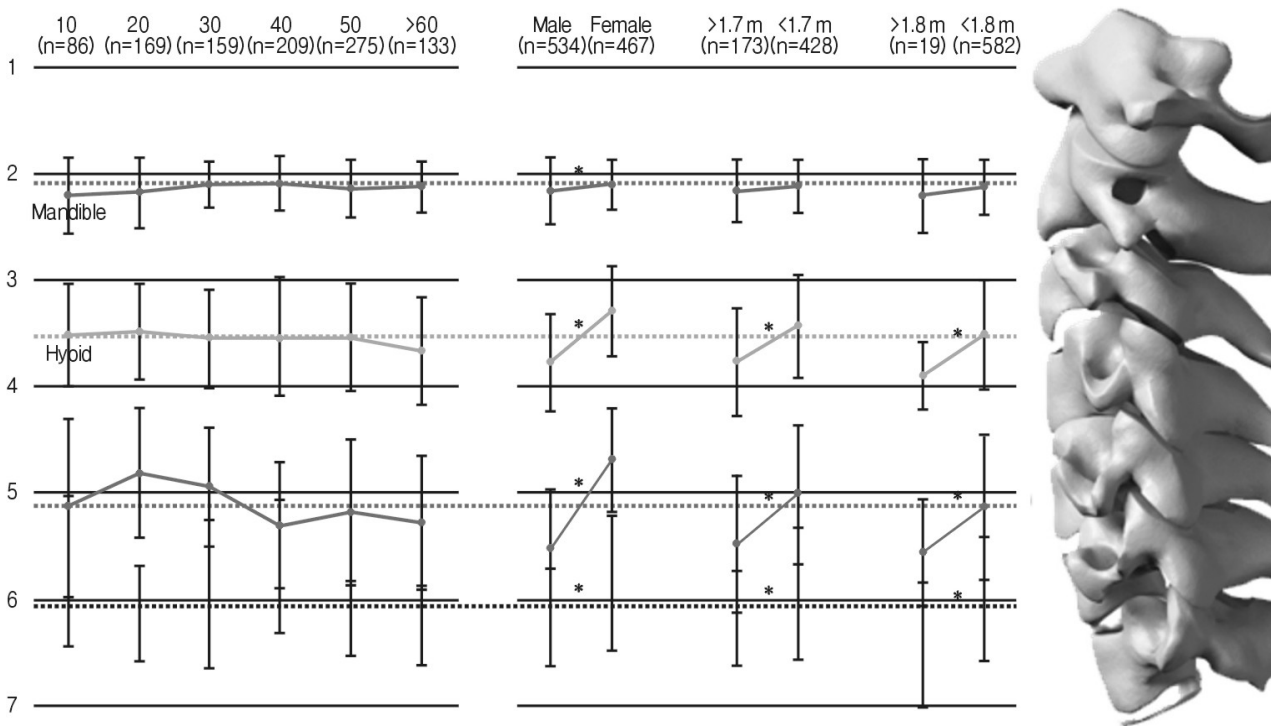

Fig. 2. Distribution of cervical external landmark according to the ages, sex or heights.
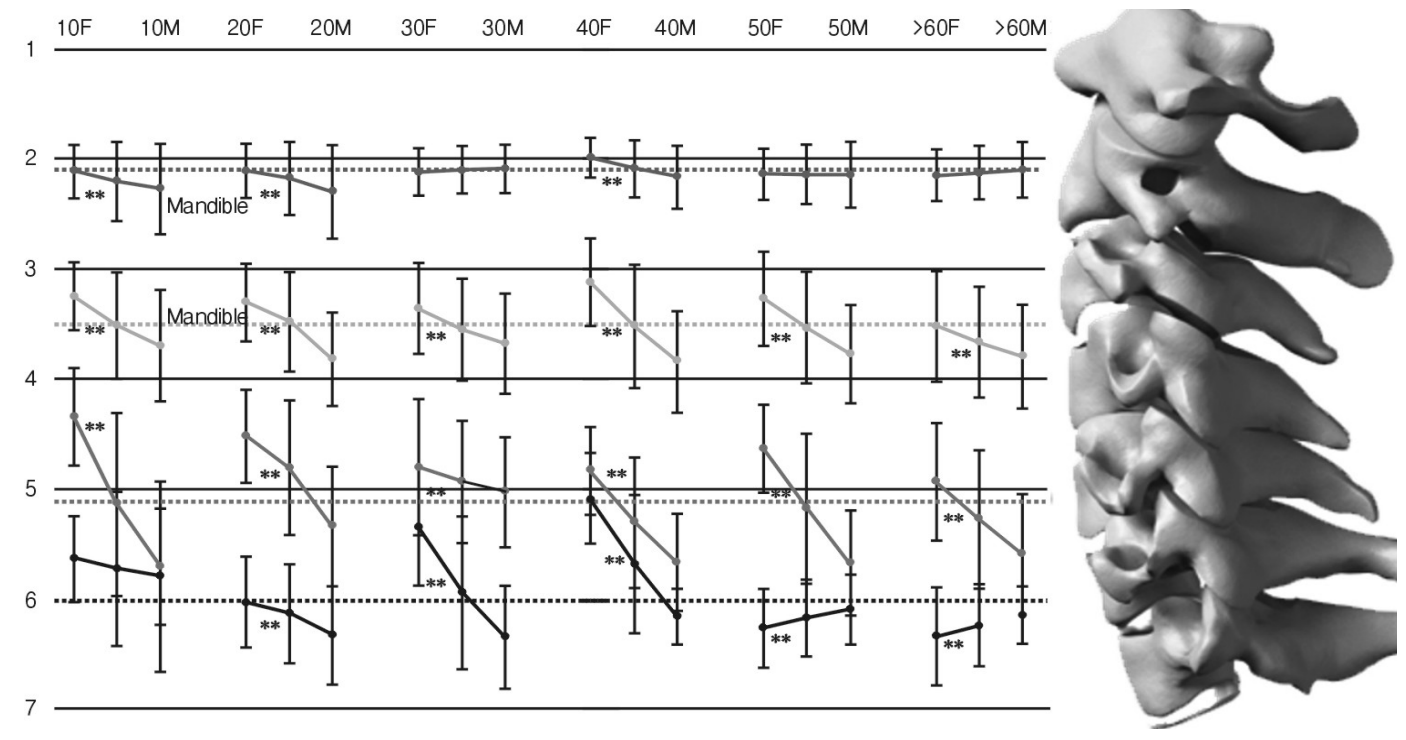

Fig. 3. Distribution of cervical external landmark according to the ages with sex.

actual differences (within 0.5 cervical level). But, the distribution of cervical reference level is also meaningfully differently observed. The male group showed more wide variety of thyroid cervical reference level (C4-C7) compared to female group (C3.5-C6). Indeed, taller subjects $(>180 \mathrm{~cm})$ showed more narrowed cervical reference level of mandible, hyoid, thyroid, and cricothyroid compared to others $(<180 \mathrm{~cm})$. The age also contributed the range of cervical reference level, and the range were slightly narrowed accordingly the ages of subjects (for example, the cricothyroid reference level was narrower from C4-C7.5 in $1^{\text {st }}$ decades to C5.5-C7 in $7^{\text {th }}$ decades. The sexual difference in same decades were presented in Fig. 3. The mandible was comparatively observed in constant level (C2-3), but, the hyoid, thyroid, and cricothyroid showed relatively wider variation of reference cervical level according to the sexes with statistical differences $(\mathrm{p}<0.05)$.

\section{DISCUSSION}

Cervical anterior approach is one of most common procedures to treat the cervical pathology. During the performing this technique, the general cervical spine estimation by external landmarks is useful, quick and less exposable to radiation techniques. So, most textbooks advert about the external landmarks for cervical operation. Yoomans neurosurgery ${ }^{5)}$ commented that "The cricothyroid membrane identifies the C6 vertebral level. The thyroid cartilage corresponds to C3-4, and the space halfway between these two points corresponds to C4-5. The angle of the jaw corresonds to C2-3. For skin 
incision, a distance of two finger-breaths above the clavicle usually to C6-7, and a distance of three fingerbreadths corresponds to C4-5. The C6 anterior tubercle can be palpated in thin patients.", Lu et al. summarized that the external landmarks as hard palate to arch of atlas, lower border of mandible to $\mathrm{C} 2-3$, hyoid to $\mathrm{C} 3$, thyroid cartilage to $\mathrm{C} 4-5$, cricoid cartilage to C6, and carotid tubercle (anterior transverse process) to $\mathrm{C}^{5}$. . The textbook of Korean Spinal Neurosurgery Society provide that general external landmarks: the hyoid bone corresonds to $\mathrm{C} 3$; the thyroid cartilage corresponds to C4-5; and the cricothyroid membrane identifies the $\mathrm{C} 6$ vertebral level ${ }^{3}$. These provided references were similar but slightly different references were observed according to different authors. In this study also different reference levels as our result indicated: C2.13 with mandible, C3.54 with hyoid, C5.12 with thyroid, and C6.01 with cricohyoid. But, the more important information is that the reference levels of cervical landmarks were differently observed by sex, age, and somatometric measurement (height) accordingly mandible from $\mathrm{C} 1$ to $\mathrm{C} 3$, hyoid from disc level of $\mathrm{C} 2$ and $\mathrm{C} 3$ to $\mathrm{C} 5$, thyroid from disc level of $\mathrm{C} 3$ and $\mathrm{C} 4$ to $\mathrm{C} 7$, and cricohyoid from $\mathrm{C4}$ to disc level of C7 and T1. This result were similar to previous other study which investigated the vertebral levels of the hard palate, hyoid bone, thyroid cartilage, cricoid cartilage, and bifurcation of the common carotid artery using computed tomography ${ }^{8)}$. Only the vertebral level of the hard palate (C1) was consistent with contemporary descriptions. Other landmarks were located most frequently at the following vertebral levels: the center of the body of the hyoid bone at C4 (54\% of cases); the superior limit of the laminae of the thyroid cartilage at $\mathrm{C} 4$ in women $(60 \%)$ and $\mathrm{C} 5$ in men $(52 \%)(\mathrm{p}=0.02)$; the inferior border of the cricoid cartilage in the midline anteriorly at $\mathrm{C} 6$ in women (37\%) and C7 in men (47\%) $(\mathrm{p}=0.008)$; and the bifurcation of the left and right common carotid arteries at C3 (left 56\%, right $62 \%)$. Vertebral levels of key bony/cartilaginous structures in the neck differ from standard descriptions but in the absence of a standardized cervical axial plane have limited value and clinical utility.

While performing the anterior approach to the cervical vertebral bodies, injury to important anatomic structures in the vicinity of the dissection represents a serious risk ${ }^{5}$. The midportion of the recurrent laryngeal nerve and the external branch of the superior laryngeal nerve are encountered in the anterior approach to the lower cervical spine. Avoiding injury to the recurrent laryngeal nerve and superior laryngeal nerve is a major consideration in the anterior approach to the lower cervical spine. The sympathetic trunk is situated in close proximity to the medial border of the longus colli at the C6 level. The damage leads to the development of Horner's syndrome. Indeed, the spinal accessory nerve (embedded in fibroadipose tissue in the posterior triangle of the neck) is prone to injury. Its damage will result in an obvious shoulder droop, loss of shoulder elevation, and pain. Prevention of inadvertant injury to the accessory nerve is critical in the neck dissection, so, the surgical level should be minimized eorros during the cervical anterior approach.

In this study, the average reference levels of cervical landmarks were C2.13 (C1.5-3) with mandible, C3.54 (C2.5-5) with hyoid, C5.12 (C3.5-7) with thyroid, and C6.01 (C4-C7.5) with cricohyoid as it showed in Table 1 and Figures. The reference levels were statistically differently observed according to the sex, age, and height, but these difference were not meaningful to clinics within 0.5 cervical level. But, these distribution of cervical reference level are meaningfully differently observed. The male group showed more wide variety of thyroid cervical reference level (C4-C7) compared to female group (C3.5-C6). Indeed, taller subjects $(>180 \mathrm{~cm})$ showed more narrowed cervical reference level of mandible, hyoid, thyroid, and cricohyoid compared to others $(<180 \mathrm{~cm})$. The age also contributed the range of cervical reference level, and the range were slightly narrowed accordingly the ages of subjects (for example, the cricohyoid reference level was narrower from C4-C7.5 in 1st decades to C5.5-C7 in $7^{\text {th }}$ decades. The sexual difference in same decades were presented in Fig. 3. The mandible was comparatively observed in constant level (C2-3), but, the hyoid, thyroid, and cricothyroid showed relatively wider variation of reference cervical level according to the sexes with statistical differences $(\mathrm{p}<0.05)$.

\section{CONCLUSION}

Surface landmarks did not correspond to exact levels of the cervical spine, and only provide general reference points. Intraoperative fluoroscopy ensures a more precise placement to the targeted cervical level.

\section{REFERENCES}

1. Xu J, Zhang K, Ma X, Yin Q, Wu Z, Xia H, et al: Systematic review of cohort studies comparing surgical treatment for multilevel ossification of posterior longitudinal ligament: anterior vs posterior approach. Orthopedics 34:e397-402, 2011

2. Lawrence BD, Jacobs WB, Norvell DC, Hermsmeyer JT, Chapman JR, Brodke DS: Anterior versus posterior approach for treatment of cervical spondylotic myelopathy: a systematic review. Spine (Phila Pa 1976) 38:S173-82, 2013

3. Baskin JJ, Vishteh AG, Dickman CA, Sonntag VKH: Anterior Cervical Instrumentation in Winn HR (eds): Youmans Neurological Surgery, ed 5. Philadelphia: W.B. Saunders, Vol 4, pp4621-4638, 2004 
4. Kim WK: Middle Cervical Approach in Korean Spinal Neurosurgery Society (eds): The textbook of Spine, ed 1. Seoul: Koonja pp377390, 2008

5. Bartolomei J, Sonntag VKH: Anterior Approach Including Cervical Corpectomy in Winn HR (eds): Youmans Neurological Surgery, ed 5. Philadelphia: W.B. Saunders, Vol 4, pp4431-4445, 2004

6. Lu J, Ebraheim NA, Nadim Y, Huntoon M: Anterior approach to the cervical spine: surgical anatomy. Orthopedics 23:841-
845, 2000

7. Kim SJ, Ju CI, Kim DM, Kim SW: Delayed esophageal perforation after cervical spine plating. Korean J Spine 10:174-176, 2013

8. Mirjalili SA, McFadden SL, Buckenham T, Stringer MD: Vertebral levels of key landmarks in the neck. Clin Anat 25:851857,2012 